\title{
Radial Paralysis in Interossal Nerve Syndrome: About A Case with Review of the Literature
}

\author{
Ismail Kabbaj $^{1 *}$, Mbarek Akanou ${ }^{1}$, Ayoub Mjidila ${ }^{1}$, Reda-Allah Bassir ${ }^{1}$, Moncef Boufetta ${ }^{1}$, Mohamed Kharmaz ${ }^{1}$, Moulay
} Omar Lamrani ${ }^{1}$, Mohamed Saleh Berrada ${ }^{1}$

${ }^{1}$ Orthopedic Surgery Department of Ibn Sina Hospital, University Mohamed V, Rabat 10100, Morocco

DOI: $10.36347 /$ sjams.2021.v09i04.005

| Received: 03.03.2021 | Accepted: 02.04.2021 | Published: 05.04.2021

*Corresponding author: Ismail Kabbaj

Abstract

Interosseous nerve syndrome is a compressive entrapment of the deep motor branch of the radial nerve in the radial tunnel. These attacks of the radial nerve constitute a rather rare but particularly interesting variety of radial palsy. We report the case of a 39-year-old woman who presented with right posterior interosseous nerve syndrome. The diagnosis was made on clinical grounds in particular the low radial palsy which was clear and without muscle atrophy. Electromyography con fi rmed the diagnosis objectifying the presence of a conduction block in the motor branch of the radial nerve. Surgical exploration revealed compression of the motor branch of the radial nerve in the arch of FROHSE. Internal neurolysis of the radial nerve was performed. Full recovery was obtained after three months.

Keywords: Palsy, Posterior interosseous nerve, Arcade of Froohse.

Copyright ( $(2021$ The Author(s): This is an open-access article distributed under the terms of the Creative Commons Attribution 4.0 International License (CC BY-NC 4.0) which permits unrestricted use, distribution, and reproduction in any medium for non-commercial use provided the original author and source are credited.

\section{INTRODUCTION}

Compression of the radial nerve at the elbow is infrequent compared to that of the ulnar nerve [1]. It is manifested by two distinct clinical presentations, either painful: radial tunnel syndrome, or paralytic interosseous nerve syndrome or supinator duct syndrome [1]. The deep motor limb is particularly vulnerable to chronic compressions [2],

Their crude symptomatology and their occurrence pose a diagnostic problem. Lateral epicondylitis can be a difficult differential diagnosis [1], although electromyography is a questionable examination. Our case reported here relates to a case of supinator duct syndrome with complete paralysis, treated by internal neurolysis.

\section{CASE RePORT}

We report the case of a 39-year-old woman with no specific history who was referred to our orthopedic surgery and trauma consultation for sudden pain on the external face of the right elbow without motor or sensory deficit. The diagnosis of epicondylitis was made and the patient was treated conservatively. One month later, the development was marked by progressive paresis of the extension of the fingers. Clinical examination revealed a deficit of extension of the 3rd, 4th and 5th finger and the right wrist (Figure-1) with radial hypoaesthesia and osteotendinous reflexes present in both upper limbs. The electromyogram (EMG) showed a collapse of the motor amplitude of the right radial nerve with normal sensory nerve conduction of the right radial nerve, as well as a neurogenic tracing in the territory of the right radial nerve. These signs were in favor of a partial axonotmesis of the right posterior interosseous nerve. The surgical treatment was carried out under locoregional anesthesia and under tourniquet, by a postero-external incision as described by Iselin [3] (Figure-2) the radial nerve was located and explored over its entire height (Figure-3) up to the fibrous band of the supinator muscle (arch of Frôhse) under which the motor branch of the radial nerve was compressed. A Wide Opening of the FROHSE arch was made to free the radial nerve (Figure-4). During the last postoperative check-up 3 months after the operation, recovery was complete without deficit.

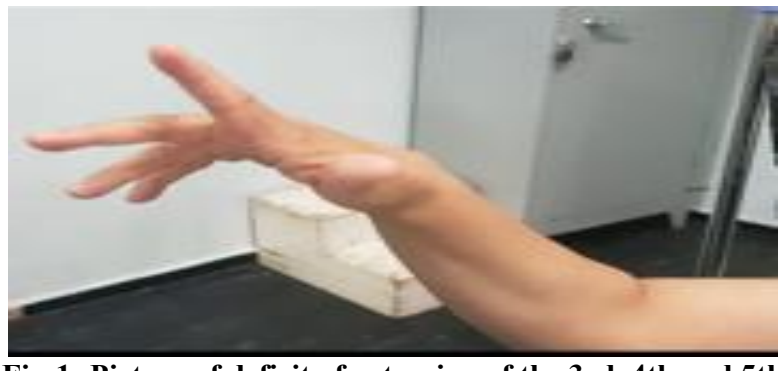

Fig-1: Picture of deficit of extension of the 3rd, 4th and 5th finger and the right wrist 


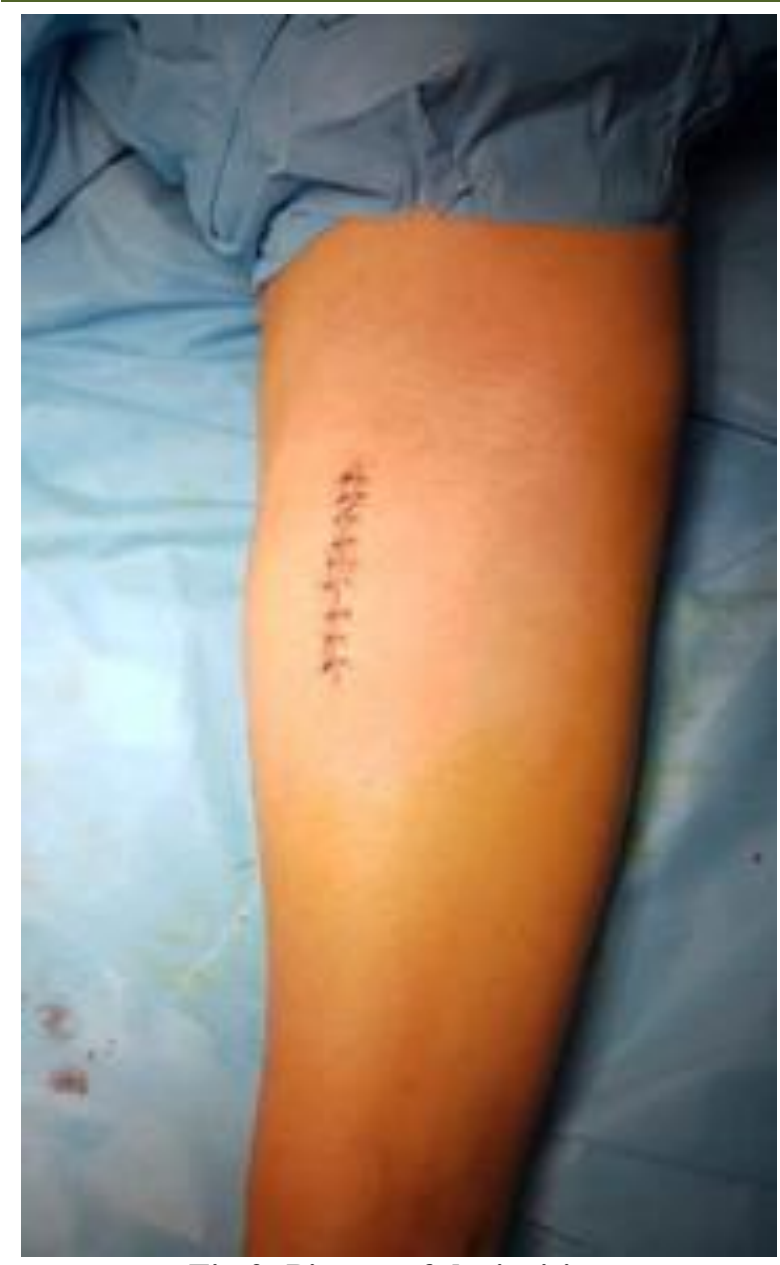

Fig-2: Picture of the incision

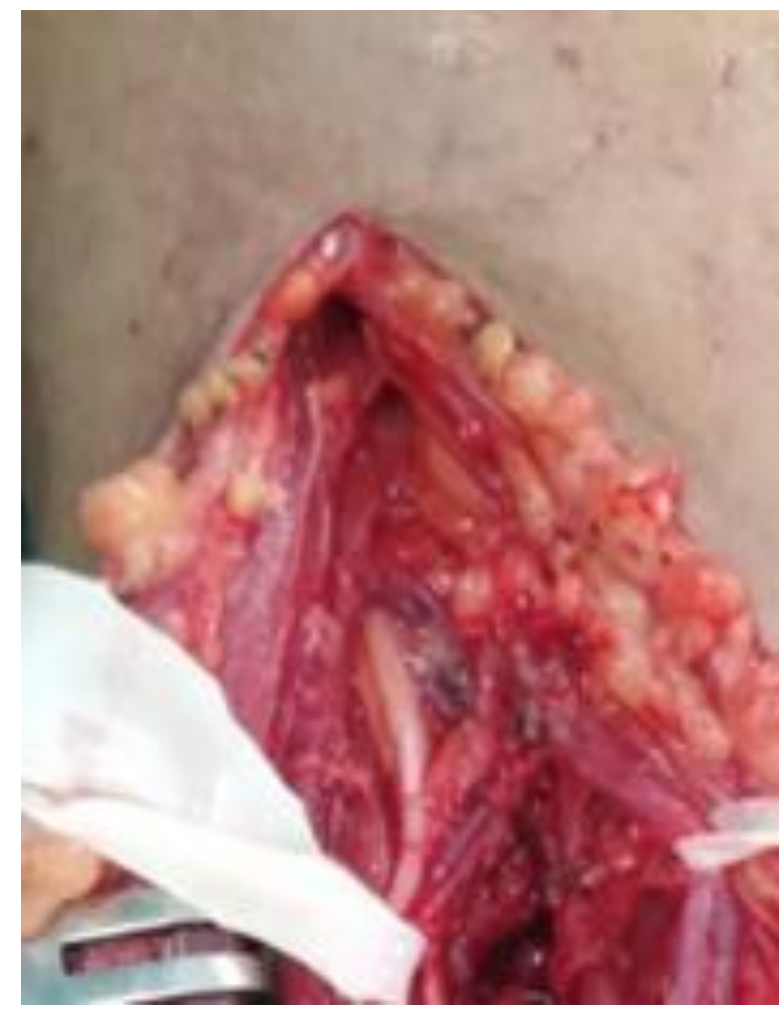

Fig-3: Picture of the bifurcation of the radial nerve

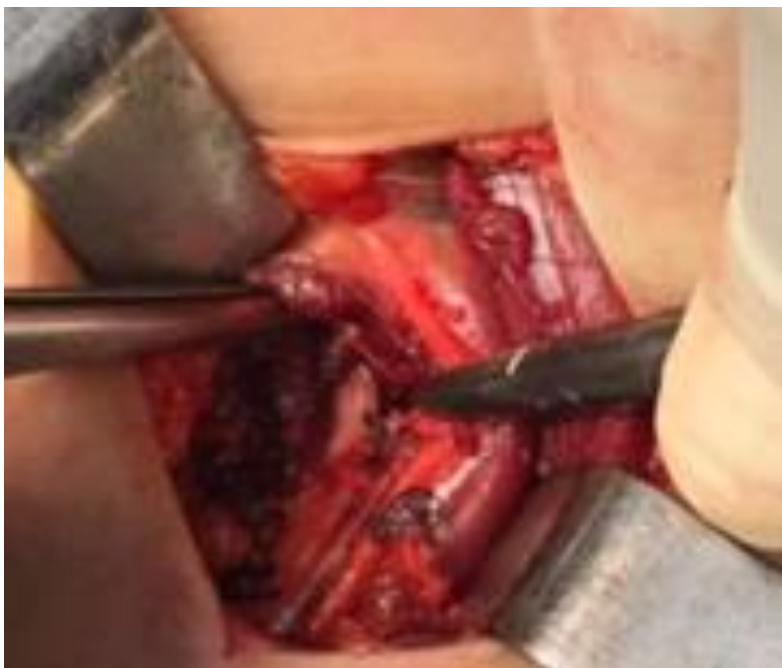

Fig-4: Picture of the wide Opening of the FROHSE arch to made free the radial nerve

\section{DisCUSSION}

Compression of the radial nerve at the elbow is infrequent compared to that of the ulnar nerve [1-4]. Knowledge of anatomical structures and their relationship to the region could provide a better understanding of the radial tunnel [2]. Spinner [5] has carried out extensive studies of the path of the radial nerve at the elbow. He pointed out that the tendon consistency of the arch is a predisposing factor for chronic compression of the deep branch of the radial nerve, especially when it is thick and provides a narrow opening for the passage of the motor branch. The other causes of compression are represented by the fibrous fibers at the entrance to the radial tunnel as well as the tendon of the second radial [6]. Indeed, pain is always found in the history of ductal syndromes. As long as there is no paresis or paralysis, it is difficult to differentiate this type of pain from that of radial epicondylitis, and the diagnostic difficulty between the latter and posterior interosseous nerve syndrome has attracted the attention of many authors [6-8].

From a clinical point of view, the pain of radial epicondylitis appears only during muscle contractions and disappears at rest whereas the pain of supinator duct syndrome onset after activity, does not decrease at rest, often continues at night and radiates. up to the wrist [9, 10]. It is associated with a progressive paralysis of the extensors of the fingers (finger by finger). This paralysis is often incomplete because it respects the radial extensors of the carpal and the supinator [1]. Neurophysiological examination does not always provide a definitive diagnosis $[8,11]$. However, in many cases of ductal syndrome, a decrease in motor conduction speed as well as subtle alterations in the EMG may be evident. 
Ismail Kabbaj et al; Sch J App Med Sci, Apr, 2021; 9(4): 521-523

Management depends on the time before consultation, age, clinical presentation, preoperative EMG and imaging results. In the event of an expansive process, the treatment is immediately surgical. Otherwise, surgical exploration is indicated within eight to twelve weeks if there is no clinical recovery or evidence of reinnervation on EMG.

The intervention can be performed by a postero-external route as described by Iselin [3] or by an anterior route depending on the origin of the compression. Neurolysis consists in freeing the radial nerve but especially the motor branch by cutting the superficial layer of the supinator muscle. In old and complete paralysis, palliative surgery is recommended in addition to neurolysis. The results are satisfactory, but still remain inferior to good neurological recovery [12].

\section{CONCLUSION}

The differential diagnosis between radial nerve duct syndrome at the elbow and radial epicondylitis sometimes remains difficult as long as there is no paralysis, Symptoms of pain at night and at rest in the elbow, radiating up to the wrist, pressure pain in the supinator canal suggesting a local nerve complication. In the case of paralysis, surgical exploration with neurolysis is required if spontaneous recovery does not appear after two to three months maximum.

\section{REFERENCES}

1. Raimbeau G, Saint-Cast Y. Compression du nerf radial au coude. Chir Main, 2004; (1 Suppl): S86S101.

2. Clavert P, Lutz JC, Adam P, Wolfram-Gabel R, Liverneaux P, Kahn JL. Frohse's arcade is not the exclusive compression site of the radial nerve in its tunnel. Orthopaedics \& Traumatology: Surgery \& Research. 2009 Apr 1;95(2):114-8.

3. Iselin F. Exposure of nerves in the upper limb. In: Michon J, Moberg E. Traumatic nerve Lesions of the Upper Limb, pp. 75-77. Monographs of the Group d'Etude de la Main. Edinburgh, Lon- don, New York. Churchill Livingstone, 1975.

4. Spinner M. The arcade of Frohse an its relationship to posterior interosseous nerve paralysis. J Bone Joint Surg, 1968; 50B: 809-12.

5. Spinner $M$. Injuries to the major branches of peripheral nerves of the forearm. 2nd Ed., 278 p., Philadelphia, London, Toronto, W.B. Saunders Company, 1978.

6. Palazz S, Palazzi C, Raimondi P, Aramburo F. Syndromes compressifs du neff radial. In : SOUQUET R. -- Syndro- mes canalaires du membre sup\&ieur, pp. 41-54. Monographie du GEM. Paris, Expansion Scientifique Frangaise, 1982.

7. Roles NC, Maudsley RH. Radial tunnel syndrome : resis- tant tennis elbow as a nerve entrapment. J Bone Joint Surg, 1972; 54B, 499-508.

8. Werner CO. Lateral elbow pain and posterior interosseous nerve entrapment. Acta Orthop Scand (suppl.), 1979; 174.

9. Heisel J, Aeckerle J. Ursache, Diagnostik u0d Therapie des Supinatortunnelsyndromes. In: Hohmann D, Kugelgen B, Liebig K. Neuroorthopiidie 3: Brustwirbel-siiulenerkrankungen, Engpasssyndrome, Chemonukleolyse, Evozierte Potentiale, pp. 323.

10. Michiels I, Boeckx W, Guelinckx P, Gruwez JA. Le syndrome du canal supinateur. A propos d'un cas de longue durde, trait6 par neurolyse interne sous vue microscopi- que. Ann Chir Main, 1987; 6(3), 216-218.

11. Paquin JM. Electromyography in peripheral nerve injuries. In: Michon J, Moberg E. Traumatic nerve lesions of the Upper Limb, pp. 19-24. Monographs of the Group d'Etude de la Main. Edin- burgh, London, New York. Churchill Livingstone, 1975.

12. Bowen TL, Stone KH. Posterior interosseous nerve paralysis caused by a ganglion at the elbow. J Bone Joint Surg. 1966; 48B: 774-6. 